\title{
Oropharyngeal Metastasis of Cardiogenic Angiosarcoma
}

\author{
Shintaro Kanda, Tomonobu Koizumi, Nobumitsu Kobayashi and Keishi Kubo
}

Key words: angiosarcoma, oropharynx metastasis

(Intern Med 51: 127-128, 2012)

(DOI: 10.2169/internalmedicine.51.6639)

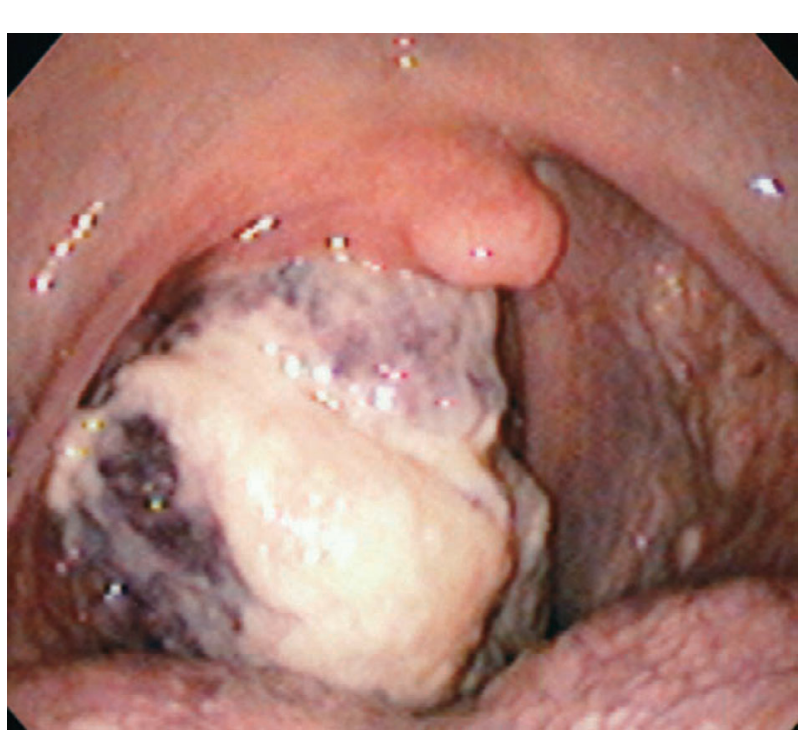

A

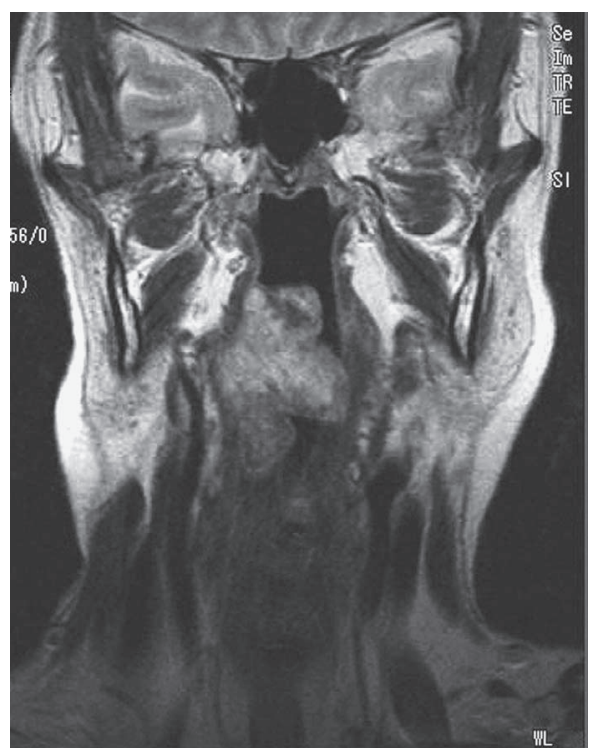

$\mathrm{B}$

Picture 1.

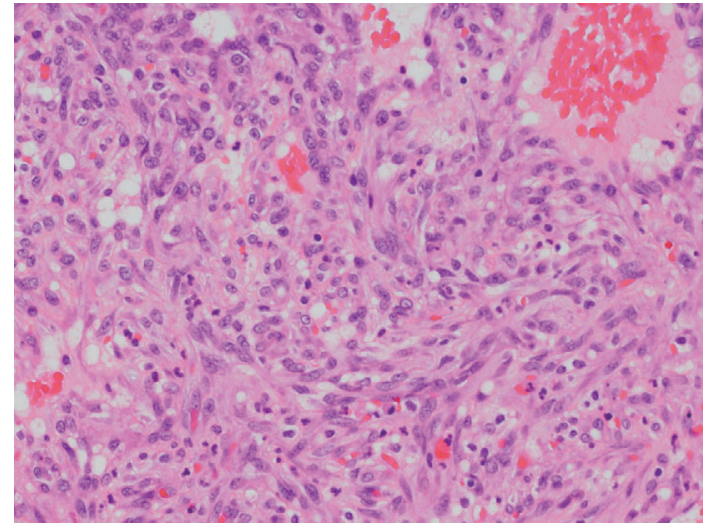

Picture 2.

A 49-year-old man was referred to our hospital because of pericardial effusion and a mass that occupied most of the right atrium space. Diagnosis of cardiogenic angiosarcoma was made by percutaneous transluminal biopsy. Thoracic radiotherapy followed by docetaxel chemotherapy was able to shrink the mass. After 10 progression-free months, the patient presented ozostomia, hoarseness and dysphagia. We found a mass in his oral cavity (Picture 1A) and cervical magnetic resonance imaging (MRI) showed a pedunculated, $40 \mathrm{~mm}$-sized, well-enhanced tumor which protruded from the right oropharyngeal wall (Picture 1B). The histology analysis revealed identical findings to the right atrium tumor (Picture 2), thus the oropharyngeal tumor was considered to be a metastasis of cardiogenic angiosarcoma. It was difficult to resect surgically, so focal irradiation was performed and necrotized the tumor. Angiosarcoma are likely to metastasize to various organs $(1,2)$, but oropharyngeal metastasis of

The First Department of Internal Medicine, Shinshu University School of Medicine, Japan Received for publication September 30, 2011; Accepted for publication October 11, 2011 Correspondence to Dr. Tomonobu Koizumi, tomonobu@shinshu-u.ac.jp 
cardiogenic angiosarcoma is rarely reported.

\section{References}

The authors state that they have no Conflict of Interest (COI).

1. Naka N, Ohsawa M, Tomita Y, Kanno H, Uchida A, Aozasa K. Angiosarcoma in Japan. A review of 99 cases. Cancer 75: 989996, 1995.

2. Fayette J, Martin E, Piperno-Neumann S, et al. Angiosarcomas, a heterogeneous group of sarcomas with specific behavior depending on primary site: a retrospective study of 161 cases. Ann Oncol 18: 2030-2036, 2007.

(C) 2012 The Japanese Society of Internal Medicine http://www.naika.or.jp/imindex.html 